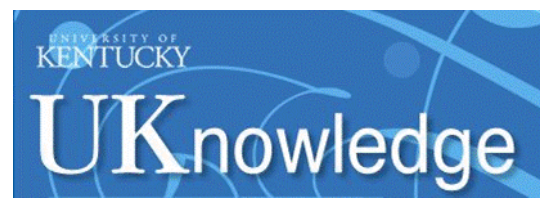

University of Kentucky

UKnowledge

\title{
A Quantitative Comparison of Arm Activity between Survivors of Breast Cancer and Healthy Controls: Use of Accelerometry
}

\author{
Mary Insana Fisher \\ University of Dayton \\ Claire C. Davies \\ Baptist Health Lexington \\ Timothy L. Uhl \\ University of Kentucky, tluhl2@uky.edu
}

Follow this and additional works at: https://uknowledge.uky.edu/rehabsci_facpub

Part of the Nursing Commons, Oncology Commons, and the Rehabilitation and Therapy Commons Right click to open a feedback form in a new tab to let us know how this document benefits you.

\section{Repository Citation}

Fisher, Mary Insana; Davies, Claire C.; and Uhl, Timothy L., "A Quantitative Comparison of Arm Activity between Survivors of Breast Cancer and Healthy Controls: Use of Accelerometry" (2020). Physical Therapy Faculty Publications. 110.

https://uknowledge.uky.edu/rehabsci_facpub/110

This Article is brought to you for free and open access by the Physical Therapy at UKnowledge. It has been accepted for inclusion in Physical Therapy Faculty Publications by an authorized administrator of UKnowledge. For more information, please contact UKnowledge@lsv.uky.edu. 


\title{
A Quantitative Comparison of Arm Activity between Survivors of Breast Cancer and Healthy Controls: Use of Accelerometry
}

\author{
Digital Object Identifier (DOI) \\ https://doi.org/10.1007/s00520-020-05365-5 \\ Notes/Citation Information \\ Published in Supportive Care in Cancer. \\ (C) 2020, Springer Nature
}

This is a post-peer-review, pre-copyedit version of an article published in Supportive Care in Cancer. The final authenticated version is available online at: https://doi.org/10.1007/s00520-020-05365-5 
Title: A Quantitative Comparison of Arm Activity between Survivors of Breast Cancer and Healthy Controls: Use of Accelerometry

Corresponding Author: Mary Insana Fisher, Department of Physical Therapy, University of Dayton, Dayton, Ohio, USA. Email; mary.fisher@udayton.edu Ph 937-229-5617

Claire C Davies, Nursing and Allied Health Research Office, Baptist Health Lexington, Lexington Kentucky, USA Tim Uhl, Department of Physical Therapy, University of Kentucky, Lexington, Kentucky, USA.

\section{Abstract}

Purpose: Survivors of breast cancer (BC) on the non-dominant side have more persistent deficits than those with cancer on the dominant limb. What is not known is whether those with BC use their involved upper limbs more, less, or at the same level as women without BC. Accelerometer use offers a quantifiable method to measure activity levels of upper limbs. The purpose of this study was to quantify the activity levels of the non-dominant involved limb among survivors of $\mathrm{BC}$, and compare these values to their dominant limb, as well as the non-dominant limb of a control group.

Methods: Participants ( $\mathrm{n}=30$ ) were women with unilateral BC on the non-dominant limb, diagnosed between 6 and 24 months prior to data collection and a matched healthy group of women as controls. Participants completed the following questionnaires: medical and demographics, Brief Fatigue Inventory, Brief Pain Inventory - Short form, Disabilities of the Arm, Shoulder and Hand (DASH), and Beck Depression Index. Participants wore an accelerometer on each wrist during waking hours for seven days. Arm activity was measured using vector magnitude activity counts extracted from the accelerometers.

Results: There was no significant differences in total vector magnitude activity counts between groups for either limb. Within group dominant to non-dominant comparison was significantly different $(p \leq 0.001)$. No significant difference in pain was present but significant differences for fatigue $(p=0.002)$, depression $(p=0.004)$, and DASH scores $(p=0.035)$ were present.

Conclusions: Women with non-dominant BC use their involved limb similar to healthy controls but less than their dominant limb.

Word count for abstract 250 with headings

Key words: Physical function, breast neoplasm, upper extremity, quality of life 
Manuscript word count 2680 with headings

All authors contributed to the study conception and design. Material preparation, data collection and analysis were performed by Mary Insana Fisher, Claire C Davies and Tim Uhl. The first draft of the manuscript was written by Mary Insana Fisher, Claire C Davies and Tim Uhl and all authors commented on previous versions of the manuscript. All authors read and approved the final manuscript.

\section{Acknowledgements}

This study was funded in part by a grant from the Academy of Oncologic Physical Therapy of the American Physical Therapy Association. 
A Quantitative Comparison of Arm Activity between Survivors of Breast Cancer and Healthy Controls: Use of Accelerometry

\section{Background and Purpose:}

Breast cancer (BC), the most commonly diagnosed cancer among women after skin cancer, was expected to affect more than 268,000 women in 2019 [1]. Over the last 25 years, 5year survival rates have increased to nearly $90 \%$ and it is estimated that over three million women are currently living with BC [1]. Therefore, as women are living beyond diagnosis and immediate treatment of BC, research is focusing on quality of life (QOL) issues and how long term deficits which negatively impact QOL can be mitigated.

Survivorship begins at the point of diagnosis and extends throughout life after diagnosis [2,3]. Understanding how treatment can impact survivorship, both in terms of QOL and overall function, is important. Lower levels of QOL post-treatment in survivors of BC may be attributed, in part, to activity limitations and participation restrictions which result from treatments for BC. Physical function scores on QOL scales decline the greatest immediately following surgical treatment for BC, but remain below baseline 6-104 weeks after treatment [4,5]. Treatments for BC including surgical management, chemotherapy, and radiation are associated with short term upper extremity functional morbidities including loss of motion [6-9], reduced strength $[6,8,10]$, decline in functional abilities [11], and the development of secondary lymphedema [12]. These deficits are greater among women who undergo more involved interventions such as axillary lymph node dissection and mastectomies, and/or axillary radiation, than the less invasive lumpectomy and/or sentinel lymph node biopsy [13,14]. Furthermore, in a portion of survivors of BC, those deficits continue longer than the expected healing time after treatment. 
Research examining the long-term functional status of survivors of BC has shown that deficits in motion and strength persist beyond the time expected for normal recovery. Range of motion deficits continued for more than 5 years in 34\% of survivors of BC after diagnosis [15], with two studies reporting the amount of loss exceeding $25^{\circ}$ flexion and abduction motion in up to $38 \%$ of survivors of BC 2-4 years after surgery [16,17]. Strength deficits are often selfreported, but in a study of 131 survivors of BC one year following surgery, an 8\% loss in shoulder abduction strength measured by hand-held dynamometry was documented compared to pre-operative status [18]. In another study of 75 women who underwent both mastectomy and axillary lymph node dissection with axillary radiation with a mean time since surgery of 15 months, flexion and abduction strength loss was 7 and 18\% respectively [19]. Many studies do not report which limb, the dominant or the non-dominant, is impacted by breast cancer treatments, despite recording whether the right or the left side is involved. Even in the studies which do report dominance, no separate analyses were conducted based on the dominance $[19,20,21]$. The preponderance of studies that lack detail about which limb is impacted by breast cancer treatments have the potential to overlook the role of dominance in recovery of upper extremity function. Yet, some important evidence shows that women who had BC on their nondominant side have more persistent deficits than those who experienced cancer on the dominant limb. In a study examining 54 women on average four years post diagnosis of unilateral BC, range of motion, strength and self-reported function were measured and compared to the respective limb in a group of women without breast cancer. That is to say, the dominant involved limb of those with breast cancer was compared to the dominant limb of women without breast cancer, and the non-dominant involved limb of those with breast cancer was compared to the non-dominant limb of women without breast cancer. The significant findings from this study 
showed differences between those with cancer on their non-dominant side compared to women with cancer on the dominant side. Importantly, those with cancer on their non-dominant limb had greater deficits in motion, strength, and self-reported function on the Disabilities of the Shoulder, Arm and Hand (DASH) than women who did not [22]. It is unclear why the deficits are greater on the non-dominant involved limb. The greater impairments and disability for those whose cancer was on the non-dominant side may exist in part because forced usage is expected on the dominant limb, while the non-dominant limb may not be engaged in the same level of activity as the dominant side. This premise that women with cancer on their non-dominant limb use their involved limb less overall needs to be further investigated.

The use of activity trackers or accelerometers is offering objective and quantifiable methods to measure the amount of activity in which upper limbs are engaged. Acuna and Karduna [23] established, in a study of 21 workers wearing an accelerometer for a day, that the amount of activity measured by the device was strongly correlated with the amount of dynamic activity in which the workers participated $(r=0.81-0.97, p<0.01)$. Other research confirmed the ability of accelerometers to measure activity at different velocities. In a study examining how well accelerometers can detect motion, 30 participants wore an accelerometer during rehabilitation exercises performed at different velocities, while completing tasks mirroring activities of daily living. The accelerometer was sensitive enough to detect motion at different velocities $(p<0.03)$, and correlated with visual activity counts for the activities of daily living $(r=.93, p<0.01)[24]$.

In order to measure the amount of activity between limbs, accelerometers must be sensitive enough to detect any differences in activity level. In a study comparing the amount of use on the dominant and non-dominant limbs as well as differences between the involved limb 
and a control group, 15 participants who were to undergo shoulder arthroplasty and 15 matched controls wore accelerometers for 3 days. Findings from this study revealed both significant differences between limbs in the experimental group ( $p<0.001$ ), as well as differences between the involved limb of the experimental group and the controls ( $p=0.03$ ) [25]. These results support similar findings in a study validating the use of accelerometry against a handedness questionnaire. Forty participants wore accelerometers on both limbs for 24 hours, and a significant correlation was found between the activity counts of the accelerometers and the handedness questionnaire [26].

The need to measure limb use among women who experienced BC on their non-dominant side is important in order to proactively educate women about arm use after BC treatment in order to mitigate long term deficits. The Prospective Surveillance Model of BC care advocates for ongoing post-treatment monitoring of functional status in order to prevent morbidities associated with BC treatments or initiate rehabilitation before impairments impact function in a more substantial manner [27]. Accelerometry offers a method to objectively quantify upper extremity activity among survivors of BC. Currently, the authors are unaware of any evidence of using accelerometers to quantify upper extremity use in survivors of $\mathrm{BC}$, therefore the primary purpose of this study is to measure bilateral upper extremity activity among women with BC and a control group. The primary hypothesis of this study is that the non-dominant involved upper extremity activity of the women treated for $\mathrm{BC}$ will be lower than a control group. The secondary hypothesis is that non-dominant limb activity will be lower than dominant limb activity in both survivors of BC and a control group.

\section{Methods}


The study recruited thirty women (15 women with unilateral BC on their non-dominant side and 15 healthy controls) ages 30-69 years between May 2014 - September 2016. Women with BC were included if they (1) had unilateral cancer stage 0-3, (2) underwent surgical treatment for breast cancer, (3) had cancer on the non-dominant side, and (4) the cancer diagnosis was between 6 months and 24 months prior to data collection. The healthy control group had no history of BC. Exclusion criteria included: (1) any history of shoulder pathology in the last 6 months other than related to BC; (2) any shoulder, neck, or thoracic surgery; (3) bilateral cancer, or (5) women with BC who were still currently undergoing BC chemotherapy or radiation treatment.

Study Design and Procedures

This investigation utilized a matched, case-control study design. This study was a multicentered study with the primary location at the University of Dayton Department of Physical Therapy, Dayton, Ohio, and the secondary location at Baptist Health Lexington, in Lexington, Kentucky. Approval was obtained by the Institutional Review Boards at both the University of Dayton and Baptist Health Lexington prior to initiating the study. After completing informed consent, participants completed five questionnaires including a medical history with demographics; fatigue; pain; depression; and arm function.

\section{Medical and Demographics Questionnaire}

Participants provided information regarding age, arm dominance, type/stage of cancer, cancer treatment including type and date of surgery, radiation, and chemotherapy, duration since diagnosis/treatment initiation, occupational work demand, and shoulder activity level by selfreport. Occupational work demand was rated sedentary, light, medium, heavy, and very heavy, using the Dictionary of Occupational Titles Physical Demands Checklist [28]. Shoulder activity 
level was measured using ratings of how much lifting, carrying, and overhead manipulation occurred on a regular basis. These self-reported activity levels were used to determine overall total self-reported activity. Investigators measured and recorded weight (in kilograms) and height (in meters) of each participant.

Fatigue: Brief Fatigue Inventory

This 9-item questionnaire is designed to assess the severity and impact of cancer-related fatigue on daily functional activity in the previous 24 hours. The time required to complete this scale is approximately 5 minutes. This scale has a reported Cronbach alpha reliability ranging from 0.82-0.97 [29], and is highly recommended by the Oncology Evidence Database to Guide Effectiveness (EDGE) Taskforce for use with survivors of BC [30].

Pain: Brief Pain Inventory - Short form

This 11-item questionnaire is designed to assess the severity and interference of pain on daily functional activity in the previous 24 hours. The time required to complete this scale is approximately 5 minutes. This scale has a reported Cronbach alpha reliability ranging from 0.770.91 [31], and is highly recommended by the Oncology Evidence Database to Guide Effectiveness (EDGE) Taskforce for use with survivors of BC [32].

Depression: Beck Depression Index

This 21-item questionnaire measures characteristic attitudes and symptoms of depression for use in multiple populations. The time required to complete this scale is approximately 10 minutes. This scale has a reported internal consistency (Cronbach alpha) ranging from 0.73-0.92 [33].

Self-reported arm function: Disabilities of the Arm, Shoulder and Hand (DASH) 
This is a reliable and valid 30-item self-report scale scored 0 to 100 , with higher scores indicating greater disability [34]. This scale has been used frequently to assess arm disability and function among women with breast cancer and is highly recommended by the Oncology Evidence Database to Guide Effectiveness (EDGE) Taskforce for use with survivors of BC [35]. Quantification of Arm Activity

Participants wore an activity tracker, or accelerometer, on each wrist during waking hours (6:00 am - 10:30 pm) for seven days. The ActiGraph GT3X+ (Actigraph, Corp., Pensacola, FL) activity monitor is a tri-axial accelerometer with a mass of 19 grams and physical dimensions of $4.6 \mathrm{~cm} \times 3.3 \mathrm{~cm} \times 1.5 \mathrm{~cm}$. The ActiGraph GT3X+ has the ability to record several measures but only the vector magnitude physical activity counts (VMPAC) were used in this study. The ActiGraph GT3X+ was set to record physical activity in the x, y, and $\mathrm{z}$ axes every 10 seconds. This activity tracker was worn during all daily activities but was discouraged during bathing or activities including water. At the completion of the seven-day period, participants returned to the lab to turn in the accelerometers. Data from the accelerometers were downloaded to a computer for further analysis using ActiLife software (Actigraph Corp., Pensacola, FL). The average hourly VMPAC was calculated by summing the total VMPAC for the waking hours, divided by the total waking hours. The average hourly VMPAC was used in analysis.

\section{Statistical Analysis}

Group demographics were analyzed with descriptive statistics and independent samples ttests for age, body mass, activity level, and self-report questionnaires (Brief Fatigue Inventory, Brief Pain Inventory, Beck Depression, and DASH). Activity counts were compared between groups and limbs using independent samples t-tests. To explore the relationship between arm 
activity levels and fatigue, pain, depression, and self-reported function, a correlation analysis using Pearson $r$ was conducted. The level of significance was set $a$ priori at $p<0.05$. Results

Groups were similar across all domains of age, body mass, and total self-reported arm function ( $p>0.05)$. Women with BC were on average 10.5 (1-21) months from surgery. Table 1 details participant demographics.

Independent samples t-test comparisons between groups for the self-report questionnaires revealed statistically significant differences between survivors of BC and control groups on three measures. Survivors of BC had higher levels of fatigue $(p=0.002)$, depression $(p=0.004)$ and scores on the DASH $(p=0.035)$ than women without cancer. No significant differences were detected in pain levels between groups ( $p=0.085-0.156)$. Mean levels of self-reported outcomes are detailed in Table 2.

Vector magnitude physical activity counts were significantly different between limbs, but not between groups. Survivors of BC did not use either the involved non-dominant limb or the non-involved dominant limb any differently than women without $\mathrm{BC}$ ( $p=0.350$ and $p=0.334$, respectively). Both groups showed significantly less use of the non-dominant limb compared to the dominate limb $(p \leq 0.001)$. See Table 3. No relationship between VMPAC and levels of fatigue, pain, depression or self-reported function $(p>0.05)$ was found.

\section{Discussion}

To our knowledge, this was the first study examining quantity of arm motion of women treated for BC using accelerometry. Results indicate that women with BC appear to use their limbs at levels comparable to women without BC, in contrast to our hypothesis that this group of survivors of BC would demonstrated lower arm activity levels than a control group. Our 
hypothesis that the non-dominant limb would demonstrate lower activity levels than the dominant limb was substantiated. This group of women with cancer on their non-dominant side used this non-dominant limb less than their dominant limb. This finding is consistent with the group of women without $\mathrm{BC}$, and with other studies examining the effect of dominance on limb use [25].

Cancer-related fatigue (CRF) is the most common side effect of cancer treatment, and prevalence ranges between $58 \%$ and $94 \%$ for women with breast cancer during treatment, with overall prevalence reported at $48 \%$ throughout the survivorship continuum [36]. The participants in this study demonstrated greater levels of fatigue and depression than their control counterparts. Studies investigating CRF also report that depression is associated with CRF, and together, CRF and depression can result in lower levels of QOL $[37,38]$. In a secondary analysis of the women with BC in this study, depression was strongly correlated with fatigue $(p<0.001$, $r=0.768$ ), consistent with other research findings. In those diagnosed with CRF, lower levels of physical activity are also reported [39]. Our results do not demonstrate a relationship between arm activity level and fatigue $(p>0.05)$. It is possible that the results related to arm activity in this study do not show a difference with a control group because we matched our groups based on occupational and self-reported arm activity levels.

Women with BC on their non-dominant limb have higher levels of self-reported disability, and less range of motion and strength than survivors of BC with involvement of their dominant limbs [22]. In this study, $60 \%$ of women had a mastectomy and/or axillary lymph node dissection, and over half underwent axillary radiation. These treatments typically result in greater disability than a lumpectomy or sentinel node biopsy. It is possible that the typically occurring lower levels of activity in the non-dominant involved limb hinder recovery efforts compared to 
women who have BC on the dominant limb. With DASH scores significantly greater among women with BC compared to the control group in this study, return to full function appears incomplete. This finding is important to understand within the context of prospective surveillance education. Rehabilitation specialists should be attentive to encouraging higher levels of usage of this limb, and should monitor impairment more closely, in order to regain pretreatment levels of functional use of the involved limb.

The DASH questionnaire scores among the survivors of BC group are higher than the control group, indicating some level of disability. It is important to understand the context of these findings. The DASH questionnaire is not limb specific. The published directions are to assess the level of difficulty completing common daily activities [34]. Some questions/activities are general such as preparing a meal, pushing open a door, carrying items, while other activities do imply use of dominant limbs. These activities include opening a jar, handling keys, writing and using a knife, and most of these activities are dominant driven. The groups of women in this study continue to report deficits despite no involvement of the dominant limb and this suggests an important role of the non-dominant limb in all activities. It is possible that supportive actions, such as stabilizing a jar when opening it, or securing food when using a knife, impact overall upper extremity function. This would need to be more closely examined.

\section{Limitations}

This study does present several limitations. This population of survivors of BC focused only on those with non-dominant involvement and did not include women with cancer on the dominant side. How the activity levels in this population of women compare to survivors of BC with cancer on the dominant side is not known. Secondly, accelerometers are limited to measuring acceleration during motion, but the magnitude of the motion or amount of elevation as 
well as the frequency the arms are lifted overhead cannot be determined. Inertial measurement units are becoming more available and may allow for more specific motions to be examined in the future. If the magnitude of motion could be captured, these findings may provide specific information for recovery of function. Lastly, only one participant had reconstruction. This single participant's data did not result in any outliers, and reconstruction was $>12$ months prior to data collection. What is not captured in this study is the potential differences in function among women with reconstruction. This may be especially relevant as the current standard of care has evolved to reconstruction at the time of mastectomy, before healing of the cancer surgery has taken place.

\section{Conclusion}

This population of breast cancer survivors and controls use the non-dominant involved arm less than the dominant arm. This could hinder recovery efforts among women with BC on their nondominant limb compared to women who have BC on the dominant limb. In prospective surveillance education, rehabilitation specialists should be attentive to encouraging higher levels of usage of this limb, and to monitor impairment more closely to mitigate long-term deficits. 
Funding: This study was funded by grant from the Academy of Oncologic Physical Therapy of the American Physical Therapy Association for the purchase of the equipment used in this study.

Conflict of Interest: Mary I Fisher, PT, PhD received a research grant for equipment from the Academy of Oncologic Physical Therapy of the American Physical Therapy Association. Claire Davies, PT, PhD, and Timothy Uhl, PhD, ATC, PT declare that they have no conflict of interest.

Data: The authors of this study have full control of all primary data, and this is available for the journal editorial board to review if requested. 


\section{References}

1. Howlader N, Noone AM, Krapcho M, et al (eds). SEER Cancer Statistics Review, 19752016, National Cancer Institute. Bethesda, MD, https://seer.cancer.gov/csr/1975_2016/, based on November 2018 SEER data submission, posted to the SEER web site, April 2019.

2. National Coalition for Cancer Survivorship (NCCS) Our Mission. NCCS - National Coalition for Cancer Survivorship. https://www.canceradvocacy.org/about-us/our-mission/. Accessed January 9, 2020.

3. Ganz PA. The 'three Ps' of cancer survivorship care. BMC Med. 2011;9:14. doi:10.1186/1741-7015-9-14

4. Kootstra J, Hoekstra-Weebers JEHM, Rietman H, et al. Quality of life after sentinel lymph node biopsy or axillary lymph node dissection in stage I/II breast cancer patients: a prospective longitudinal study. Ann Surg Oncol. 2008;15(9):2533-2541.

5. Mutrie N, Campbell AM, Whyte F, et al. Benefits of supervised group exercise programme for women being treated for early stage breast cancer: pragmatic randomised controlled trial. BMJ. 2007;334(7592):517-517.

6. Blomqvist L, Stark B, Engler N, Malm M. Evaluation of arm and shoulder mobility and strength after modified radical mastectomy and radiotherapy. Acta Oncol. 2004;43(3):280283.

7. Rietman JS, Dijkstra PU, Geertzen JHB, et al. Short-term morbidity of the upper limb after sentinel lymph node biopsy or axillary lymph node dissection for Stage I or II breast carcinoma. Cancer. 2003;98(4):690-696.

8. Hayes S, Battistutta D, Newman B. Objective and subjective upper body function six months following diagnosis of breast cancer. Breast Cancer Res Treat. 2005;94(1):1-10. 
9. Tengrup I, Tennvall-Nittby L, Christiansson I, Laurin M. Arm morbidity after breastconserving therapy for breast cancer. Acta Oncol. 2000;39(3):393-397.

10. Merchant CR, Chapman T, Kilbreath SL, Refshauge KM, Krupa K. Decreased muscle strength following management of breast cancer. Disabil Rehabil. 2008;30(15):1098-1105.

11. Schmitz KH, Speck RM, Rye SA, DiSipio T, Hayes SC. Prevalence of breast cancer treatment sequelae over 6 years of follow-up: the Pulling Through Study. Cancer. 2012;118(8 Suppl):2217-2225.

12. Hayes SC, Johansson K, Stout NL, et al. Upper-body morbidity after breast cancer: incidence and evidence for evaluation, prevention, and management within a prospective surveillance model of care. Cancer. 2012;118(8 Suppl):2237-2249.

13. Peintinger F, Reitsamer R, Stranzl H, Ralph G. Comparison of quality of life and arm complaints after axillary lymph node dissection vs sentinel lymph node biopsy in breast cancer patients. Br J Cancer. 2003;89(4):648-652.

14. Nesvold I, Dahl AA, Lokkevik E, Mengshoel AM, Fossa SD. Arm and shoulder morbidity in breast cancer patients after breast-conserving therapy versus mastectomy. Acta Oncol. 2008;47(5):835-842.

15. Tengrup I, Tennvall-Nittby L, Christiansson I, Laurin M. Arm Morbidity after Breastconserving Therapy for Breast Cancer. Acta Oncol. 2000;39(3):393-397.

16. Rietman JS, Geertzen JH, Hoekstra HJ, et al. Long term treatment related upper limb morbidity and quality of life after sentinel lymph node biopsy for stage I or II breast cancer. Eur J Surg Oncol. 2006;32(2):148-152. 
17. Nesvold I, Foss SD, Holm I, Naume B, Dahl AA. Arm/shoulder problems in breast cancer survivors are associated with reduced health and poorer physical quality of life. Acta Oncol. 2010;49(3):347-353.

18. Rietman JS, Dijkstra PU, Debreczeni R, Geertzen JH, Robinson DP, De Vries J. Impairments, disabilities and health related quality of life after treatment for breast cancer: a follow-up study 2.7 years after surgery. Disabil Rehabil. 2004;26(2):78-84.

19. Blomqvist L, Stark B, Engler N, Malm M. Evaluation of arm and shoulder mobility and strength after modified radical mastectomy and radiotherapy. Acta Oncol. 2004;43(3):280283.

20. Shamley, D., Srinaganathan, R., Oskrochi, R. et al. Three-dimensional scapulothoracic motion following treatment for breast cancer. Breast Cancer Res Treat. 118, 315 (2009) doi:10.1007/s10549-008-0240-x

21. Shamley D, Lascurain-Aguirrebena I, Oskrochi R, Srinaganathan R. Shoulder morbidity after treatment for breast cancer is bilateral and greater after mastectomy. Acta Oncol. 2012;51(8):1045-1053.

22. Fisher MI, Capilouto G, Malone T, Bush H, Uhl TL. An Observational Study Comparing Upper Extremity Function in Women With and Without a History of Breast Cancer . Phys Ther. 2019; DOI: 10.1093/ptj/pzaa015.

23. Acuna M, Karduna AR. Wrist activity monitor counts are correlated with dynamic but not static assessments of arm elevation exposure made with a triaxial accelerometer. Ergonomics. 2012;55(8):963-970.

24. Lawinger E, Uhl TL, Abel M, Kamineni S. Assessment of Accelerometers for Measuring Upper-Extremity Physical Activity. J Sport Rehabil. 2015;24(3):236-243. 
25. Hurd WJ, Morrow MM, Kaufman KR. Tri-axial accelerometer analysis techniques for evaluating functional use of the extremities. J Electromyogr Kinesiol. 2013;23(4):924-929.

26. Tokuda K, Lee B, Kurihara J, et al. Analysis of Laterality in Upper Limb Function during Simulated Range of Motion Limitation Using Long-term Portable Accelerometer Recordings. Rigakuryoho Kagaku. 2013;28(1):15-20.

27. Stout NL, Pfalzer LA, Springer B, et al. Breast Cancer-Related Lymphedema: Comparing Direct Costs of a Prospective Surveillance Model and a Traditional Model of Care. Phys Ther. 2012;92(1):152-163.

28. United States Department of Labor. United States Employment Service, and the North Carolina Occupational Analysis Field Center. Dictionary of Occupational Titles (DOT): Revised Fourth Edition, 1991. Ann Arbor, MI: Inter-university Consortium for Political and Social Research [distributor], 2006-01-12. https://doi.org/10.3886/ICPSR06100.v1

29. Cella D, Viswanathan HN, Hays RD, et al. Development of a fatigue and functional impact scale in anemic cancer patients receiving chemotherapy. Cancer. 2008;113(6):1480-1488.

30. Farnen Price W, Doherty D, Adams A, Bohde E. Breast Cancer EDGE Task Force Outcomes: Evidence-based Cancer-related Fatigue Measurement Tools. Rehabil Oncol. 2014;32(3):32-39 38p.

31. Cleeland CS, Ryan KM. Pain assessment: global use of the Brief Pain Inventory. Ann Acad Med Singapore. 1994;23(2):129-138.

32. Harrington S, Gilchrist L, Sander A. Breast Cancer EDGE Task Force Outcomes: Clinical Measures of Pain. Rehabil Oncol. 2014;32(1):13-21.

33. Beck AT, Steer RA, Carbin MG. Psychometric properties of the Beck Depression Inventory: Twenty-five years of evaluation. Clin Psychol Rev. 1988;8(1):77-100. 
34. Solway S, Beaton D, McConnell S, Bombardier C. The DASH Outcome User's Manual. 2nd ed. Toronto, Ontario: Institute for Work and Health; 2002.

35. Miale S, Harrington S, Kendig T. Oncology Section Task Force on Breast Cancer Outcomes: Clinical Measures of Upper Extremity Function. Rehabil Oncol. 2013;31(1):2734.

36. de Jong N, Candel MJ, Schouten HC, Abu-Saad HH, Courtens AM. Prevalence and course of fatigue in breast cancer patients receiving adjuvant chemotherapy. Ann. Oncol. 2004;15(6):896-905

37. Lis CG, Gupta D, Grutsch JF. The relationship between insomnia and patient satisfaction with quality of life in cancer. Support. Care Cancer. 2008;16(3):261-266

38. Schultz SL, Dalton SO, Christensen J, Carlsen K, Ross L, Johansen C. Factors correlated with fatigue in breast cancer survivors undergoing a rehabilitation course, Denmark, 20022005. Psychooncology. 2011;20(4):352-360.

39. Gerber LH, Stout N, McGarvey C, et al. Factors predicting clinically significant fatigue in women following treatment for primary breast cancer. Support. Care Cancer.

2011;19(10):1581-1591 
Table 1. Demographic Characteristics - Mean (SD)

\begin{tabular}{|l|l|l|l|}
\hline & Breast Cancer $(\mathrm{n}=15)$ & Control $(\mathrm{n}=15)$ & $p$ value \\
\hline Age (years) & $55(10)$ & $54(9)$ & 0.763 \\
\hline Body Mass Index $(\mathrm{kg} / \mathrm{m} 2)$ & $30.22(4.41)$ & $27.89(6.44)$ & 0.259 \\
\hline Activity Level & $13.77(3.11)$ & $14.67(3.70)$ & 0.497 \\
\hline Months from diagnosis & $10.5(4.7)$ & & - \\
\hline Type of Surgery & $\begin{array}{l}\text { Lumpectomy =5 } \\
\text { Mastectomy = 4 } \\
\text { Lumpectomy + ALND = 3 } \\
\text { Mastectomy + ALND = }\end{array}$ & & \\
\hline Axillary Radiation & $\mathrm{n}=8$ & - & - \\
\hline
\end{tabular}

Table 2. Self-Report Measures - Means (SD)

\begin{tabular}{|l|l|l|l|}
\hline Outcome measure & Breast cancer $(n=15)$ & Healthy Control $(n=15)$ & $p$ value \\
\hline DASH & $21.57(24.91)$ & $4.94(9.58)$ & $0.035^{\star}$ \\
\hline Fatigue & $3.52(2.17)$ & $1.24(1.44)$ & $0.002^{\star}$ \\
\hline Pain Severity & $3.27(2.11)$ & $1.73(1.81)$ & 0.085 \\
\hline Pain Interference & $2.32(2.54)$ & $1.06(1.52)$ & 0.156 \\
\hline Beck Depression & $11.69(7.07)$ & $3.27(2.76)$ & $0.004^{\star}$ \\
\hline
\end{tabular}

DASH Disability of Arm Shoulder and Hand Questionnaire; BFI Brief Fatigue Inventory; BPI severity Brief Pain Inventory short form severity; BPI interference Brief Pain Inventory short form interference; Beck Depression Inventory ; * $\alpha$ significant at the $p<0.05$ level

Table 3. Arm Activity - Means (SD)

\begin{tabular}{|l|l|l|l|}
\hline & Breast cancer $(\mathrm{n}=15)$ & Controls $(\mathrm{n}=15)$ & $p$ value \\
\hline VMPAC Dominant & $138,187(35945)$ & $151,461(37990)$ & 0.334 \\
\hline VMPAC Non-Dominant & $115,123(31143)$ & $127,214(38148)$ & 0.350 \\
\hline$p$ value & $\leq 0.001^{*}$ & $\leq 0.001^{*}$ & \\
\hline
\end{tabular}

VPMAC = vector magnitude physical activity counts; ${ }^{*} \alpha$ significant at the $p<0.05$ level 